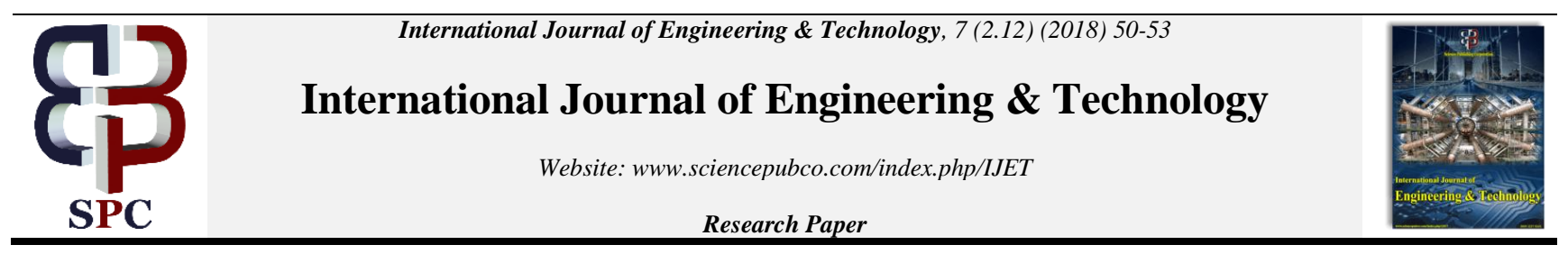

\title{
Pattern analysis of risk situations using multi-sensor
}

\author{
Chang-Bae Noh ${ }^{1 *}$, Miyang Cha ${ }^{2}$ \\ ${ }^{1}$ Department of Electronic and Radio Engineering Kyung-Hee University, Yongin, KSO09, Republic of Korea \\ ${ }^{2}$ Department of General Education Namseoul University, Cheonan, KSO02, Republic of Korea \\ *Corresponding author E-mail: zzomenyduck@empas.com
}

\begin{abstract}
Background/Objectives: Existing crime prevention systems manually monitor risk situations using street lights, CCTVs, and security equipment. Since there are many areas where the workforce is held responsible, it is difficult to closely manage all systems due to work overload.

Methods/Statistical analysis: The data of maps constructed and continuously updated through the system will allow more accurate predictions of crime and contribute to crime prevention strategies. Furthermore, replacing existing patrol manpower to unmanned drones will allow for more efficient human resources management as well as contribute to the crime prevention infrastructure, thereby minimizing the existence of blind spots in the current system.

Findings: It is not easy to diffuse the initial situation in the case of an emergency through prompt notifications. Therefore, a low-cost, integrated management system is needed to prevent major accidents and to minimize damage by detecting crime and fire risks in the early stage. It will be easier to judge risks if we use the multi-sensor and pattern analysis algorithms proposed in this study. Occurrences of crime and fire have been rapidly rising with the quick pace of industrialization. This has resulted in an increase of unease among citizens as well as a rising demand for security and safety in residential environments. As the times change, it is necessary to develop advanced science technology that can predict crimes in order to construct crime preventing environments. The Risk Notification Service can promptly respond to the current status and situation of the user by forwarding the status to the administrator or guardian. Police activity can be strengthened by building a high-tech science and security system to monitor areas susceptible to crime in real-time.

Improvements/Applications: This study looks into problems of the existing monitoring system and proposes an integrated control system for crime prevention.
\end{abstract}

Keywords: Multi-Sensor; Fire; Crime; Situation Recognition; Pattern Analysis Algorithm

\section{Introduction}

Since 'risk situation' in the context of daily life is fairly broad, this paper limits it to the conditions of crime and fire. Fires result in enormous property damage every year, and the occurrence rate is continuously increasing. Thus, it is urgent to construct facilities and take measures to prevent them.

Also, theft is rapidly increasing its occurrence with the quick pace of industrialization nationwide. This has resulted in an increase of unease among citizens as well as a rising demand for security and safety in residential environments.

An analysis of various types of crimes considered risk situations shows that crimes occur mainly in areas susceptible to crime. Crime should be prevented by improving such vulnerable environments through street lights, CCTVs, and security facilities, and by managing the environment and a systematic monitoring system.

This study proposes a multi-sensor system that analyzes the patterns of risk situations in order to prevent various risks at a low cost as a convergence industry for crime prevention and disaster management.

As there is a rising demand for policing due to the increasing occurrence and extent of crimes, it is important to design an environment that can prevent crime by reducing the number of vulnerable areas and strengthening natural surveillance system and the security system of residential areas. However, since there is a problem of work overload in the existing management workforce, it is urgent to establish new countermeasures to prevent and manage crime with a small workforcein figure 1.

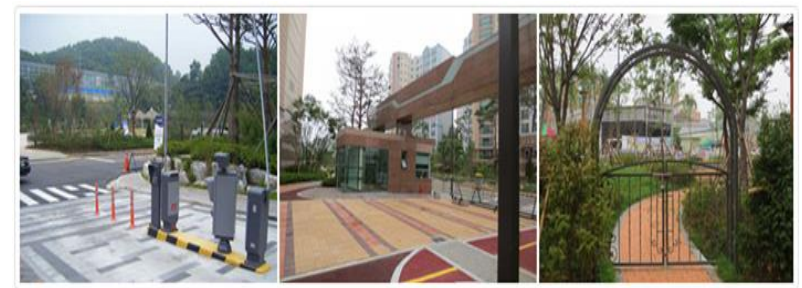

Fig. 1: Natural Surveillance Facilities for Strengthening Access Control

\section{Materials and methods}

Theft is rapidly increasing its occurrence with the quick pace of industrialization nationwide. This has resulted in an increase of unease among citizens as well as a rising demand for security and safety in residential environments. Recently theft is seeing a decrease in occurrence, but the past 10 years have seen an overall increase of theft by $22.8 \%$ in figure 2 . 


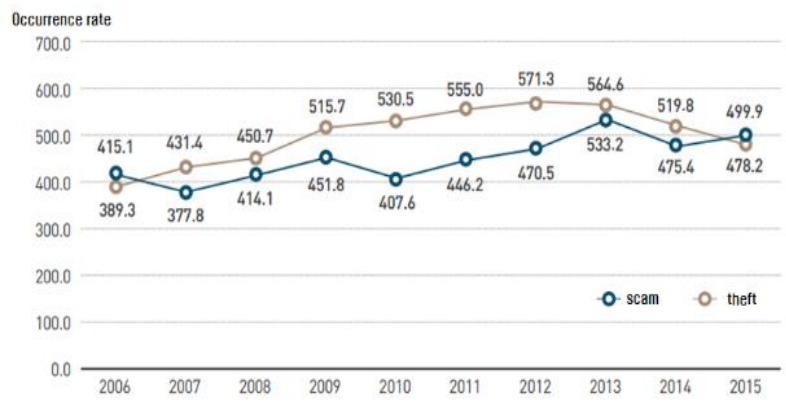

Fig. 2: Occurrence of Crime by Incident and Percentage per Type (20062015).

SIFT is largely composed of two stages. As seen in Figure 1, the first step of SIFT is identifying the key point in order to attach a descriptor to it. Following this is the matching stage, which utilizes the aforementioned descriptor for a comparison of the original DB image and target image in figure 3.

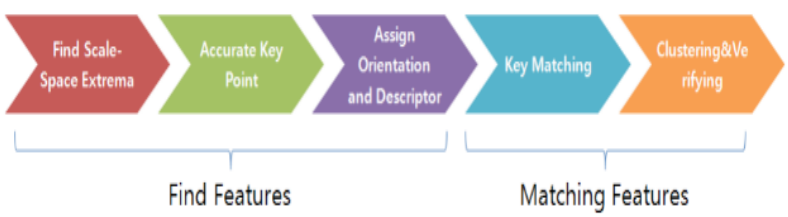

Fig. 3: SIFT Image Matching.

In the initial stage, features of the images are identified on various scales and are designated values that contain information about the direction and size of each feature. In the following stage, a matching procedure takes place based on the differences between the previously calculated features of the DB and those of the target. The matched features are categorized as being either inliers or outliers determined by the Hough transform, in order to provide an accurate match. The Least mean square is used to verify the accuracy of the match made in the last step. This is also known as the Gaussian Distribution and can be written out as Formula (1) and Formula (2) as seen below ${ }^{1}$.

$$
\begin{aligned}
& f_{x}(\mathrm{x})=\frac{1}{\sqrt{2 \pi \sigma}} \mathrm{e}^{\frac{-(\mathrm{x}-\mu)^{2}}{2 \sigma}} \ldots \ldots \ldots . \\
& \int_{-\infty}^{\infty} f_{x}(x) d x=1 \ldots \ldots \ldots \ldots \ldots
\end{aligned}
$$

The process of recognition is as such: characteristic features are first identified, followed by the identification of the trend of shape changes surrounding the feature. The trends are then compared in order to differentiate the subjects. The SIFT algorithm, although it may only seem related to computers or mathematics at first glance, is an algorithm that has been formed based on the intellect of many scientists and various scientific principals ${ }^{1}$ in figure 4 .

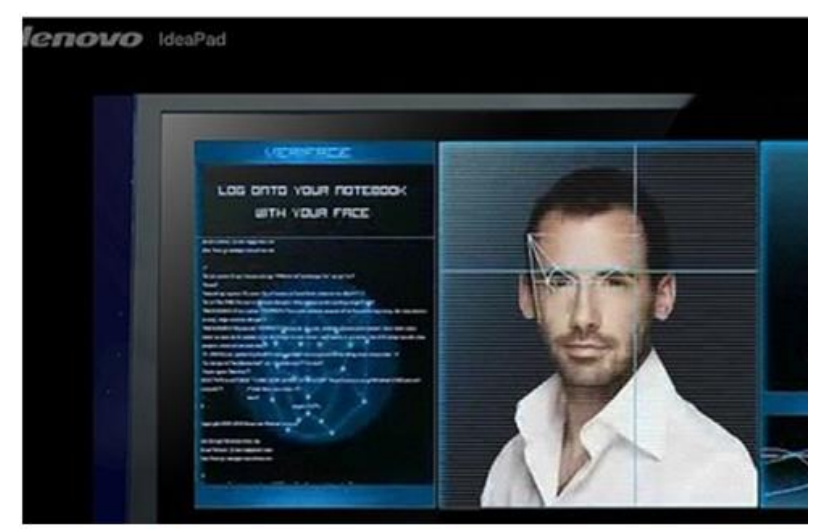

Fig. 6: Facial Recognition Technology Utilized in the System
The environment data sensor is a tool that can help keep users safe by analyzing danger patterns based on the data collected from surrounding areas. Its function includes a distress signal requesting help to surrounding individuals in case of danger in figure 5.

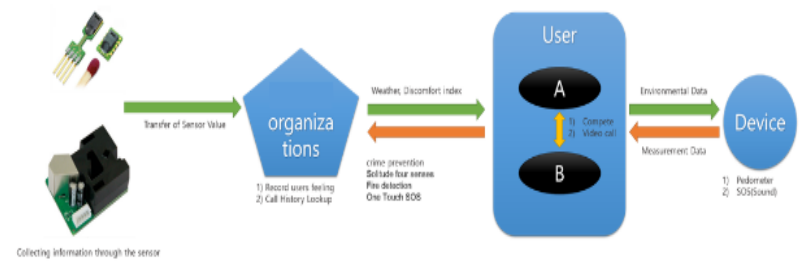

Fig. 5: F Diagram of Overview.

Computation for context awareness aims to collect data about the user's movements and environment that can be analyzed by artificial intelligence, which then decides on a course of action. The process of providing users with information or services related to their work is called a "situational awareness system". By using a mobile device to collect data, and then classifying the data collected into categories such as the user's status, the physical environment status, the computing system status, and other statuses to extract the desired data [2], [3] in figure 6 .

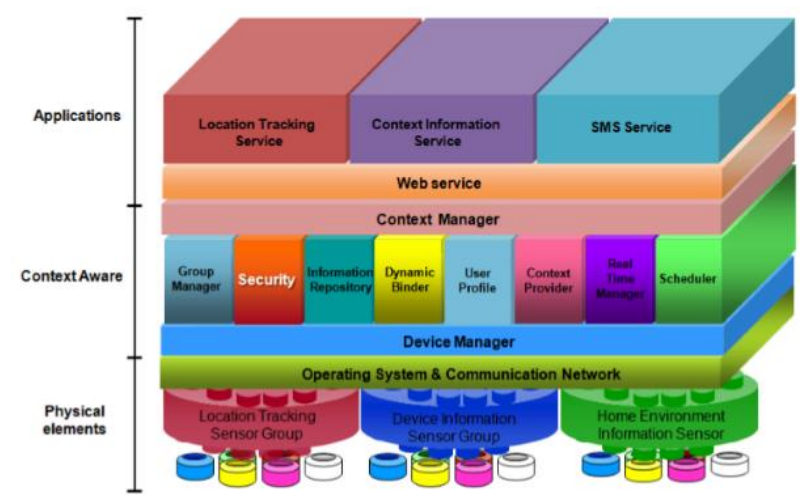

Fig. 6: Sensor, Devices, Information, Their Groups.

Existing studies include those that study information collected by acceleration sensors [4]; those utilize the accumulated data in smart phones' location-based services to analyze the relationship between time and users' movement for marketing studies [5]; those that analyze the context of the situation by analyzing the users' movements using smart devices [6]; and those that study zone deviations for personal safety that includes research [7] on methods of recognition for of crisis situations when users have deviated from the expected movement path [8].

The United States is implementing changes to their environment to increase security and revitalize in local communities; developing and running programs to raise community awareness; and introducing and spreading certification systems. For example, New York went from being riddled with various crimes to being praised as one of the safest metropolis in the world in 2013 after allowing police forces to question suspicious persons on the street. However, the decision was found to be unconstitutional after controversies arose regarding discrimination against minorities and increasing tensions between the black community and the police. In 2014, New York Mayor Bill de Blasio ceased the practice of 'stop-and-frisk' [9]. Since then, the practice has become more demanding, requiring police to state the reason for random questioning and to provide Info Cards that can be used as proof of their identity. Prior to the change, the city of New York released guidelines for the new procedure in figure 7 . 


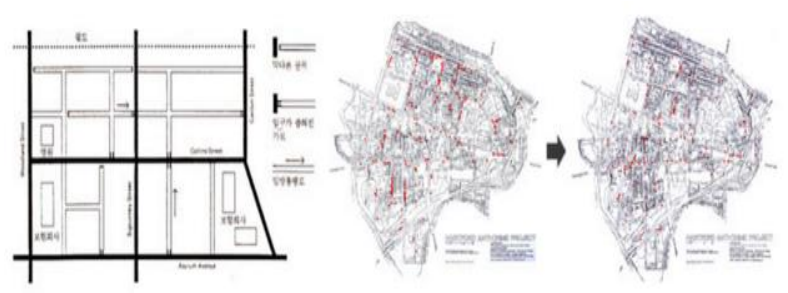

Fig. 7: Hartford City's Crime Prevention Project and Reduction in Crime Rates.

England implemented a Secured by Design (SBD) system for crime prevention; removed spaces and buildings susceptible to crime; promoted of crime prevention actions; introduced facility planning and deployment techniques to increase surveillance; and implemented regional security measures. Japan introduced a crime prevention model apartment complex certification system, as well as introduced model apartments and parking lot systems, housing, roads, parks, public facilities all with reinforced and managed with crime prevention systems. Suspicious persons are investigated, including methods such as intimidation and placation during questioning as well as identity verification and inspection of belongings. Such 'stop-and-frisk' practices are not only limited to designated areas but are mobile, via patrolling police cars.

In the case of Thailand, there are reportedly many unwarranted questionings of citizens. The police force is utilized for systematic stops, frisks, threats of detainment, and in some extreme cases, demands for bribes. If citizens are not able to immediately provide documents to prove their identity, they are taken to the police station until the problem is resolved or detained according to the Tha judicial system. Legally, stop-and-frisks are only allowed when suspects can be reasonably expected to commit crimes or possess illegal items acquired through crimes, but this is not properly observed in figure 8 .

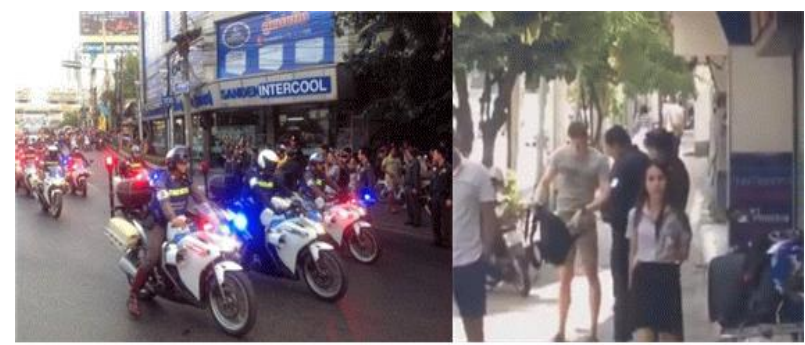

Fig. 8: Example of Thailand's Stop-and-Frisk Practice.

A characteristic of the security industry is that each country's demand and priorities are shaped by their respective natural environment and societal traits. While developed countries possess most of the source technology in the industry, it is expected that the market size in developing countries will rapidly expand once low-priced products are circulated and therefore contribute to improvements in security [10] in figure 9 .

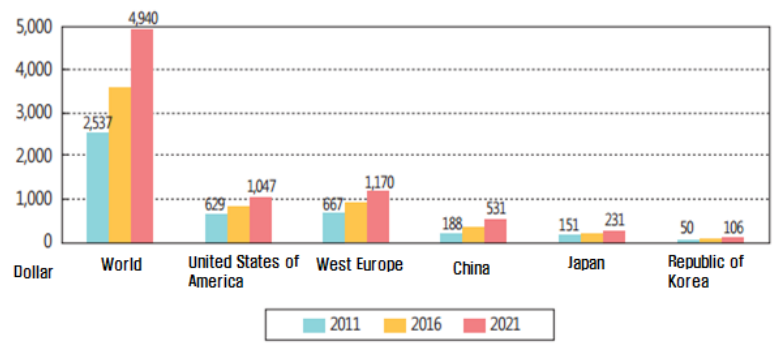

The Freedonia Group(2014).

Fig. 9: Security Market Sizes

In Korea, as in other countries, the government conducts stop-andfrisks with the consent of its citizens and follows a legal procedure.
Citizens have the right to refuse questioning and can claim for damages if they are subject to questioning in an unfair manner. Currently in 2017, many services being researched and developed in various fields of Big Data using machine learning, and there are various researches being actively conducted for the implementation of crime prediction and preventive management systems ${ }^{3}$ in figure 10 .

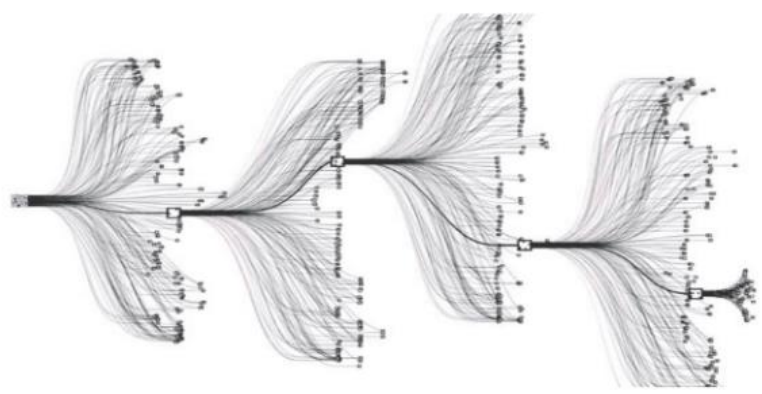

Fig. 10: Big Data Analysis

\section{Results and discussion}

We have developed a real-time crime preventing environment and an integrated control system through unmanned drones and an image pattern analysis system that works in limited conditions, and have identified a situation that is considered to be dangerous. It is necessary to construct a system that can recognize crimes as they occur by analyzing behavioral patterns of people in the unmanned drone patrol route, can view crimes as they occur in real time, and can manage the device. It will lead to revitalization of industries that can be future growth engines, boosts in local economies, and crime prevention.

Unmanned patrol automation systems utilizing unmanned drone technology enables highly efficient surveillance with low manpower, and the blind spots within the existing patrol time can be minimized. The systematic management of the patrol results and crime occurrence rates has the advantage of analyzing crime riddled areas and taking action in advance.

Utilizing Bluetooth 5.0-based wireless communication systems, it can transmit and receive low power long distance data and maximize travel time in figure 11.

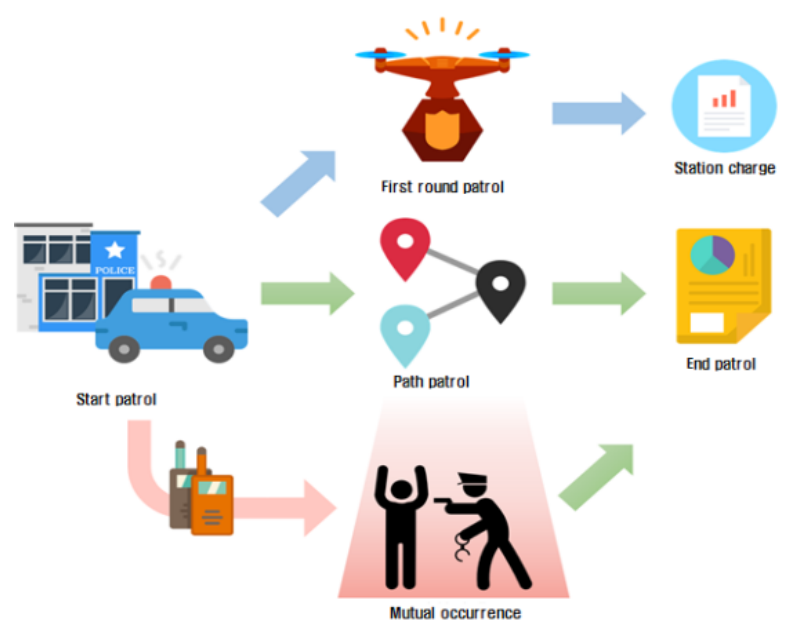

Fig. 11: Proposed Process

The user registers with photographs of family members. When the user is out, intruders can be detected by matching the persons entering the house with the images registered in the server. We aim to develop algorithms that can learn faces by storing images in the server when they are not recognized properly even if they are family members.

Furthermore, it is expected that the service will be able to handle dangerous situations efficiently if the function to notify the situation 
to a sensor is linked with the user when the user reports in figure 12.

\begin{tabular}{|c|c|c|c|}
\hline \multicolumn{2}{|c|}{ Drone } & \multicolumn{2}{|c|}{ Docking Station } \\
\hline \multirow{3}{*}{ battery } & Bluetooth 5.0 & \multirow{3}{*}{$\begin{array}{l}\text { Charging } \\
\text { circuit }\end{array}$} & Bluetooth 5.0 \\
\hline & $\begin{array}{l}\text { Risk detection } \\
\text { system }\end{array}$ & & $\begin{array}{c}\text { Signal } \\
\text { transmission } \\
\text { system }\end{array}$ \\
\hline & Sensor Board & & Sensor Board \\
\hline \multicolumn{4}{|c|}{$\begin{array}{c}\text { Integrated control system } \\
\quad \text { (Crime Hazard Area Map) }\end{array}$} \\
\hline
\end{tabular}

Fig. 12: Proposed System.

A remote control using smartphones is made with Bluetooth technology. The Bluetooth setting is requested when moving to the remote control tab. For security purposes, only the user of the device can control the system. If a user tries to register a QR code containing the other device's value to the Bluetooth, the application is forcibly terminated. CRC (Cyclic Redundancy Check) is used to verify data reliability in Bluetooth communication. The error probability of the CRC16 verification is $\mathrm{p}=2^{-16}=1 / 65536=$ $0.0000152587890625=0.0015 \%$. That is, the data reliability is $1-$ $\mathrm{p}=0.9999847412109375$ and can be calculated as $99.9984 \%$ in figure 13.

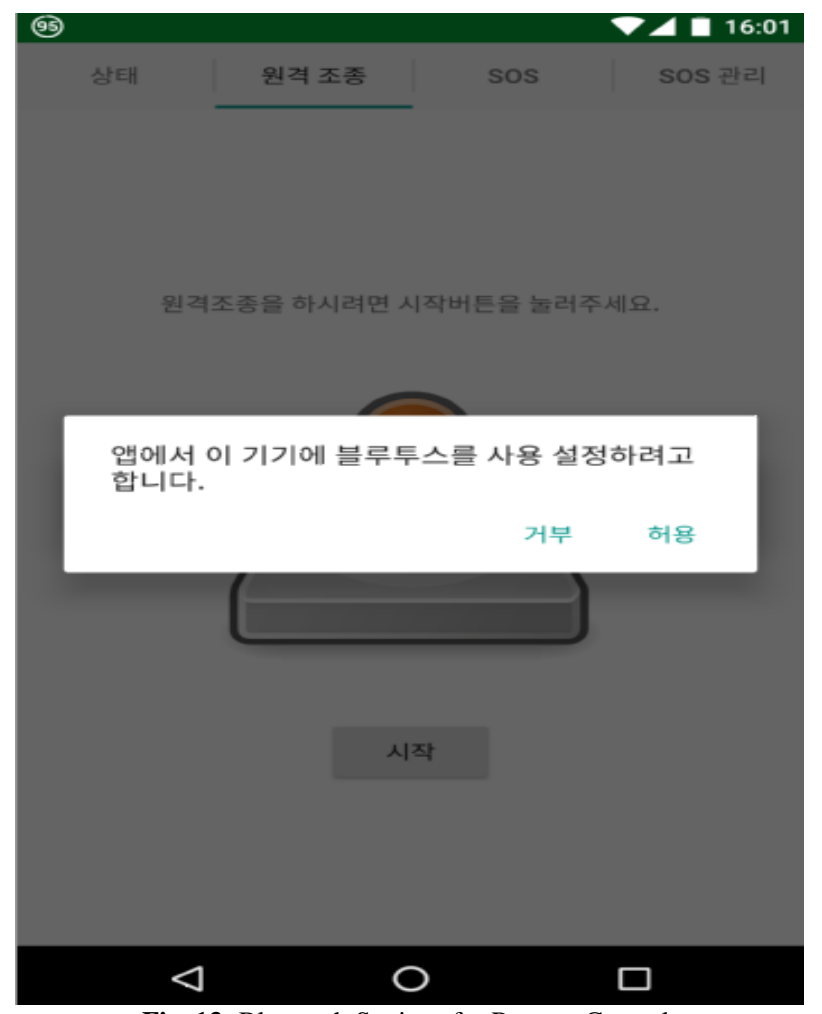

Fig. 13: Bluetooth Settings for Remote Control.

The Risk Notification Service can promptly respond to the current status and situation of the user by forwarding the status to the administrator or guardian.

\section{Conclusion}

As this paper has researched so far, we will be able to develop efficient solutions based on image pattern analysis technology to identify and analyze life-threatening situations such as crime or fire in real time. Also, if the proposed system can manage the risk factors for crime or fire and minimize and prevent the accident, the quality of life will be increased. These advanced systems could send notifications of risks and remotely manage and secure fire alarms, and alert people with safety concerns. If we can prevent massive damage by rapid notification of risks, we will be able to construct a safer society and increase the stability of life.

\section{Acknowledgment}

Funding for this paper was provided by Namseoul University.

\section{References}

[1] Bay H, Tuytelaars T, Gool LV, Surf: Speeded up robust features in Computer Vision. ECCV, 2006, 404-17.

[2] Yang J, Parekh R, Honavar V, Dobbs D. Data-driven theory refinement algorithms for bioinformatics. IJCNN '99, International Joint Conference on Neural Networks, 1999, 6:4064-8.

[3] Faye Mitchell, the Use of Artificial Intelligence in Digital Forensics: An Introduction. Digital Evidence \& Elec. Signature L. Rev, 2010.

[4] P.S. Jeong and Y.H. Cho, Fall Detection System using Smartphone for Mobile Healthcare. Journal of the Korea Society for IT Services, Vol. 12, No. 4, pp. 435-447, 2013.

[5] J.G. Lim, K, Y. Lee, and K.P. Sim, A Method of Determining Whether a Smart-Phone is Moving. Journal of Korea Multimedia Society, 2012, Vol. 15, No. 5, pp. 632-638.

[6] M.S. Hong and N.H. Mok, A Method of Determining the User's State of Movement based on the Smart Device Usage. Journal of the Korea Society for Industrial Systems, 2012, Vol. 18, No. 6, pp. 5159.

[7] J.H. Choi, A Study on Detection of Zone Departure for Personal Safety. Master's Thesis of Andong National University of Multimedia Engineering, 2013.

[8] Chang-Bae Noh and Miyang Cha, A Study on the Mobile Device using an Environmental Information-Collecting Sensor.Indian Journal of Science and Technology, 2016, Vol 9(46).

[9] Elizabeth R. Groff et al, Forecasting the Future of Predictive Crime Mapping. Crime Prevention Studies, 2002, Vol.13.

[10] Vinothini M, Umamakeswari A. Reliable data transmission using efficient neighbor coverage routing protocol in Wireless Sensor Network. Indian Journal of Science and Technology. 2014, 7(12):211823. 